\title{
The Effect of Red Palm Oil Concentration towards Characteristics and Biodegradability of PLA-Starch Film
}

\author{
Siti Fatma Abd Karim*, Nur Aliah Adilla Mohammad Asri, Rabiatul Adawiyah Abdol Aziz, and Ummi \\ Kalthum Ibrahim
}

Faculty of Chemical Engineering, Universiti Teknologi MARA, 40450 Shah Alam, Selangor, Malaysia

\author{
* Corresponding author: \\ tel: $+6017-7789215$ \\ email: sitifatma9633@uitm.edu.my
}

Received: August 2, 2019

Accepted: December 26, 2019

DOI: $10.22146 /$ ijc. 48453

\begin{abstract}
Polylactic acid (PLA) is a biodegradable polymer that had been used as a substitute for conventional petroleum based plastics. Plasticizers were added into the solution of PLA and starch (PLA/S) to increase the flexibility and degradability of the produced film. PLA/S films need plasticizers that able to improve the degradation process. Red palm oil (RPO) were incorporated into PLA/S blends. The films were casted into petri dish via casting method. The films were characterized based on the color, thickness and chemical composition (Fourier-transform infrared spectroscopy). The performance of the films was analyzed based on tensile strength and biodegradation percentage. The films were yellowish in color with the addition of RPO. The FTIR shows that the increment of $R P O$ concentration modified the intermolecular interaction between the PLA/S molecules. The tensile strength of PLA decreased with the addition of starch. The biodegradability test was done by using soil burial method where the samples were buried in peaty soil for 12 days. The films produced from these combinations resulted in a good biodegradable activity. The films with high concentration of RPO and presence of starch degraded 100\% within 12 days. RPO can be used as the plasticizer with further improvement.
\end{abstract}

Keywords: film packaging; polylactic acid; red palm oil; starch

\section{- INTRODUCTION}

Active film packaging had been developed in food industry to increase the shelf life of the food. The main goal in this area is to ensure that the food quality is in its best condition and can be maintained for the long term. Traditionally, petroleum-based food packaging is used as the food packaging. However, due to its low degradability and harmful features, biodegradable and edible film packaging using natural ingredients had been developed [1]. Polylactic acid (PLA) is a type of polymers used to produce food packaging. PLA had caught people attention as it can be chemically synthesized from agricultural resources [2]. PLA is a biodegradable thermoplastic that can be derived from the natural resources or through fermentation or chemical synthesis of lactic acid monomer [3]. Starch is a natural polymer that consists of linear polysaccharides and branched molecules that can promote the elastic properties that needed in the development of the thermoplastic. Starch based films had been one of the materials used in the film packaging production. This is due to its physical characteristics that similar to synthetic polymers which are odorless, tasteless, transparent and resistant to the $\mathrm{O}_{2}$ passage [4-5]. Combination of PLA and starch (PLA/S) blends produced brittle film. Moreover, PLA/S films causes deterioration in terms of mechanical strength. According to Wang et al. [6], large and rigid particles cannot toughen the polymer matrix. From previous studies, it had been shown that a very poor interfacial adhesion between the hydrophobic PLA and hydrophilic starch [6]. Therefore, additives were added to toughening the blends. Researchers had found some methods that can toughen the combination matrix including addition of plasticizers. Plasticizers are commonly used as an ingredient to increase the flexibility of the polymers and improving their process ability [7] by improving the mechanical properties of the starch film. Sufficient amount of plasticizer will increase 
the molecular mobility and increase the elongation at break point of the film [8-9]. PLA requires plasticizer to increase its ability to plastic deformation. Palm oil consists of triglycerides and unsaturated fatty acid which favors to be used as the plasticizer. In this study, red palm oil (RPO) were added as a plasticizer to improve the PLA and starch-based food packaging. By the addition of these materials, the quality of the produced film increased and can be commercialized. The objectives of this study was to develop and characterized a film food packaging from PLA/S/RPO blends and analyze the mechanical properties and biodegradability of the films.

\section{- EXPERIMENTAL SECTION}

\section{Materials}

Polylactic Acid (PLA) resin was used (NatureWorks ${ }^{\circledR}$ ). Red Palm Oil (RPO) used from IKO natural product with purely refined of $100 \%$ natural crude palm oil. The potato starch used from Bendosen with $\mathrm{pH}$ value at 6.7. The starch has white and crystal luster appearance. Chloroform with molecular weight of $119.380 \mathrm{~g} / \mathrm{mol}$ and density of $1.490 \mathrm{~g} / \mathrm{cm}^{3}$ was used as a solvent to dissolve the PLA resins. Chloroform was gained from R\&M chemicals.

\section{Procedure}

\section{Preparation of the film}

As for the PLA/starch/RPO films, PLA solution was mixed with the starch powder and stirred for $4 \mathrm{~h}$ or until the starch was completely dissolved. Then, different volume of RPO was added into the solution. The optimum volume of plasticizer into the PLA film was 5\% of the PLA volume [10]. The solution was stirred for another $4 \mathrm{~h}$ before being casted in the glass petri dish with a radius of $70 \mathrm{~mm}$. The samples were left to dry at room temperature for $24 \mathrm{~h}$ before being peeled and stored in a sealable plastic bags to avoid contamination. Eight samples were prepared consisting of PLA pure, PLA/RPO $(0.25 \mathrm{~mL}$, $0.5 \mathrm{~mL}$ and $1 \mathrm{~mL}), \mathrm{PLA} / \mathrm{S}$ and PLA/S/RPO $(0.25 \mathrm{~mL}$, $0.5 \mathrm{~mL}$ and $1 \mathrm{~mL}$ ).

\section{The thickness and color of the film}

The thickness was measured using digimatic micrometer by Mitutoyo at room temperature. The thickness was measured for five different areas before calculating the average thickness. The color of each produced films were tested using the chromameter. Three readings were taken for each sample at different areas. The average value was used to determine the final color placement in the color chart.

\section{Fourier transform infrared spectroscopy (FTIR)}

The FTIR spectra of control and blend films were recorded at $8 \mathrm{~cm}^{-1}$ resolution and in the range between 400 to $4000 \mathrm{~cm}^{-1}$ at room temperature. FTIR analysis used to determine the stretching vibrations of the bonds and the components of each sample.

\section{Tensile properties (tensile strength and elongation at break)}

The samples were cut lengthwise and cross direction $60 \mathrm{~mm} \times 15 \mathrm{~mm}$. For tensile strength, the load range and appropriate grip of testing machine. The extensometer measured the load versus extension was recorded. The testing speed was at $500 \mathrm{~mm} / \mathrm{min}$ with using load cell of $2.5 \mathrm{kN}$. The distances between the two anchorages was $40 \mathrm{~mm}$. The maximum load, width and thickness were recorded. Tensile strength represents the film resistance to elongation. The following formula was used to calculate the tensile strength and percentage of elongation.

$$
\begin{aligned}
& \text { Tensilestrength }=\frac{\text { maximum load }}{\text { width }(\mathrm{cm}) \times \text { thickness }(\mathrm{cm})} \\
& \text { \%elongation }=\frac{\text { break distance }}{\text { gauge length }} \times 100 \%
\end{aligned}
$$

\section{Biodegradability test}

The soil was prepared with soil samples from peaty soil from a palm tree plantation in Kuala Selangor. Films of $4 \mathrm{~cm}^{2}$ were scaled and the initial weight of the samples were measured. Four sets of samples were prepared for this test. The samples then being put into soil at a depth of $8 \mathrm{~cm}$ from the soil surface. Sixty $\mathrm{mL}$ of water was added to the samples daily. The biodegradation tests were performed at the ambient temperature. The samples were retrieved after 12 days. The samples were cleaned with a brush and cleaned using distilled water to remove the soil debris. Then, it was dried in an oven at $80^{\circ} \mathrm{C}$ for $24 \mathrm{~h}$. after drying, the weights of the samples 
were measured and recorded to assess the average weight loss (\%WL) [11].

\section{- RESULTS AND DISCUSSION}

\section{Films Thickness and Color}

Fig. 1 shows the average thickness of the films. The thickness of the film increased when the RPO concentration increased. However, there is a slight reduction of thickness at $0.5 \mathrm{~mL}$ RPO. Film with starch shows higher thickness compared to film without starch. The addition of starch into the film blends will increase the thickness of the films due to the domain structure of immiscible polymer blend [12]. The result obtained at $0.5 \mathrm{~mL}$ RPO for both films with and without starch showed the lowest thickness perhaps due to less plasticization effect occur at lowest concentration.

Fig. 2 shows the color produced by the films. Addition of RPO into the PLA/S solution had affected the

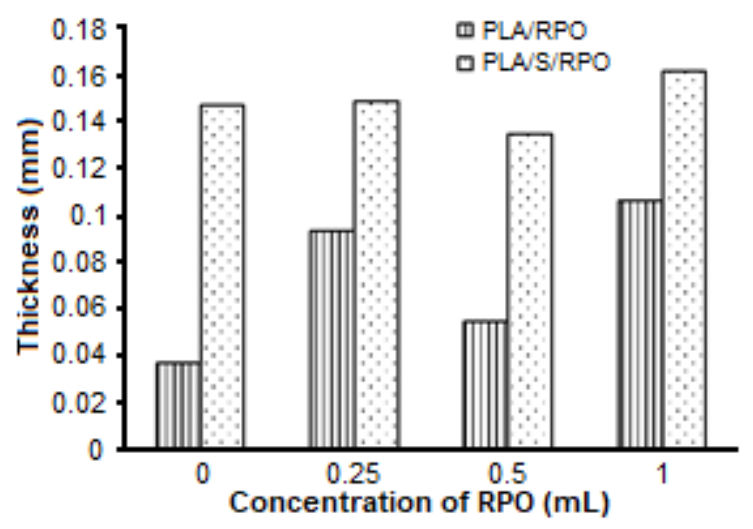

Fig 1. Thickness of the films

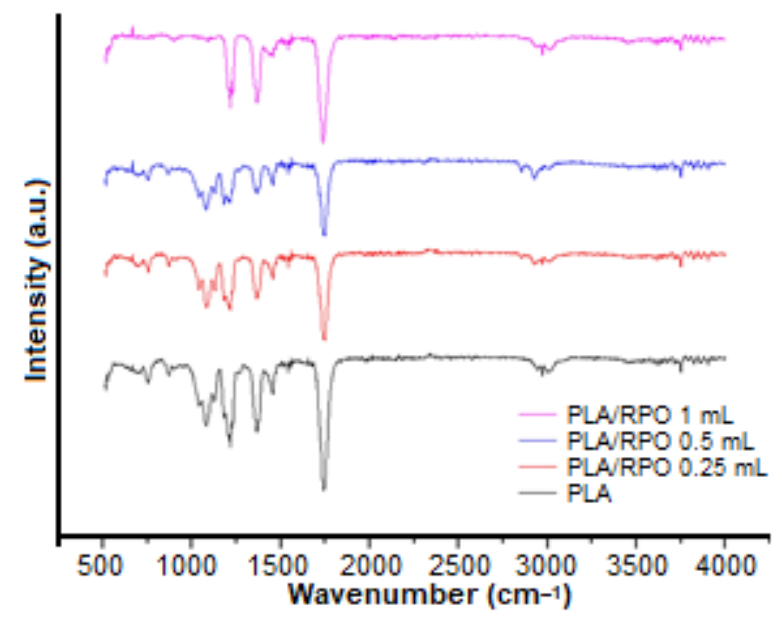

Fig 3. FTIR spectrum for PLA/RPO films color of the film. The film appears to be yellowishcolored. This is due to the nature of RPO which is redorange color and the presence of beta-carotene in the oil. PLA/RPO $0.5 \mathrm{~mL}$ yielded more luminous which resulted higher DeltaE* value. The data gained from the chromameter being analyzed by using the color chart. Pure PLA film performed clear and transparent color while film of PLA/S blends in group of white color. Starch reduces the transparency of the film. Plasticizer affected the opacity and physical appearance of the film [8]. Higher concentration of RPO may had increased the PLA film luminosity [13]. Thus, performing more luminous film packaging.

\section{Fourier Transform Infrared Spectroscopy (FTIR)}

Fig. 3 shows the FTIR for PLA/RPO films and Fig. 4 shows the result for PLA/S/RPO film. Peaks $1080 \mathrm{~cm}^{-1}$ indicate the $\mathrm{C}-\mathrm{O}$ stretching as according to Sanyang et al.,

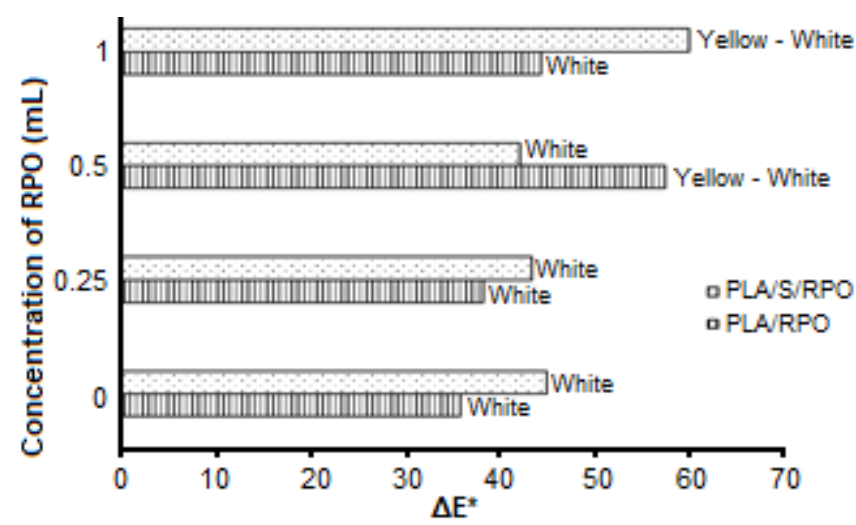

Fig 2. The color of the films

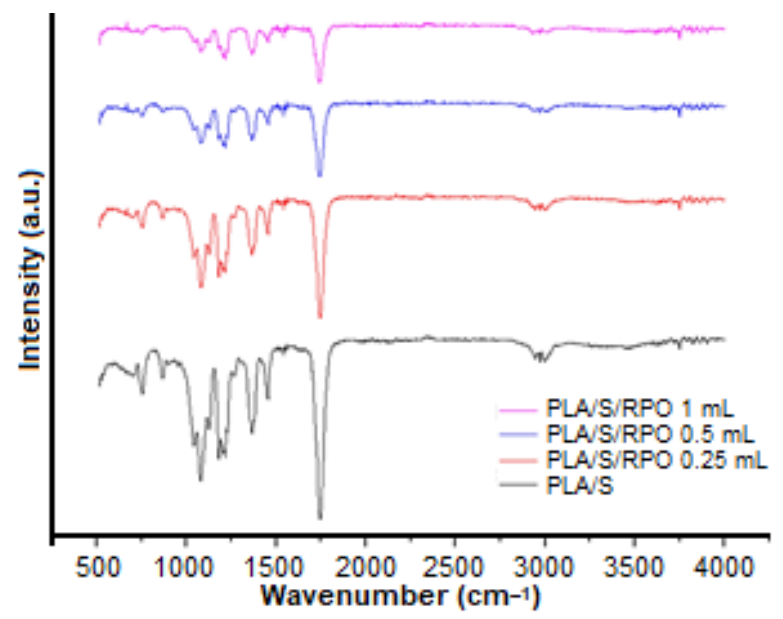

Fig 4. FTIR spectrum for PLA/S/RPO films 
the peaks attributed to this bonds are range from 1100$950 \mathrm{~cm}^{-1}$ [14]. This also had been reported by Ref [15-16]. PLA/S blends showed the absorption spectra at $1082 \mathrm{~cm}^{-1}$ due to the saccharide structure. The peak corresponded to the $-\mathrm{C}-\mathrm{H}$ deformation is at $1380 \mathrm{~cm}^{-1}$. RPO are mainly consists of $50 \%$ saturated and $50 \%$ of unsaturated fatty acids. A significant increment for $-\mathrm{C}-\mathrm{H}$ deformation in the PLA blends film. The absorbance peak at $1290-1180 \mathrm{~cm}^{-1}$ shows the esters stretching vibrations. The peak decreases as the concentration of RPO increases. The value of percentage of transmittance decreases from $1287 \mathrm{~cm}^{-1}$ to $1272 \mathrm{~cm}^{-1}$. This shows that the ester molecular bonds, $\mathrm{O}=\mathrm{C}-\mathrm{OR}$ being interrupted and loosen its intermolecular bond [17]. Small alteration of peak from $1078 \mathrm{~cm}^{-1}$ (pure PLA film) to $1085 \mathrm{~cm}^{-1}$ (PLA/RPO $1 \mathrm{~mL}$ ). This alteration in the absorption peak indicates that the miscibility and interaction of PLA and RPO. The peaks at 1500 to $1000 \mathrm{~cm}^{-1}$ indicates the region of oil. This has also reported by previous researchers [18-19].

The absorption band at $1745 \mathrm{~cm}^{-1}$ shows $-\mathrm{C}=\mathrm{O}$ bonds stretching vibrations of carbonyl. Based on the obtained result, all of the samples shows the absorbance peak at $1738-1745 \mathrm{~cm}^{-1}$ which represented the $\mathrm{C}=\mathrm{O}$ bonds stretching. This represents the stretching vibrations of carbonyl on ester group in PLA. The absorbance decreases as the concentration of RPO increases. The FTIR spectra shows at $1746 \mathrm{~cm}^{-1}$ that indicates the triglyceride ester linkage. This shows that PLA, starch and RPO link to each other in the film. There is a change in the FTIR spectra was observed at 1747 to

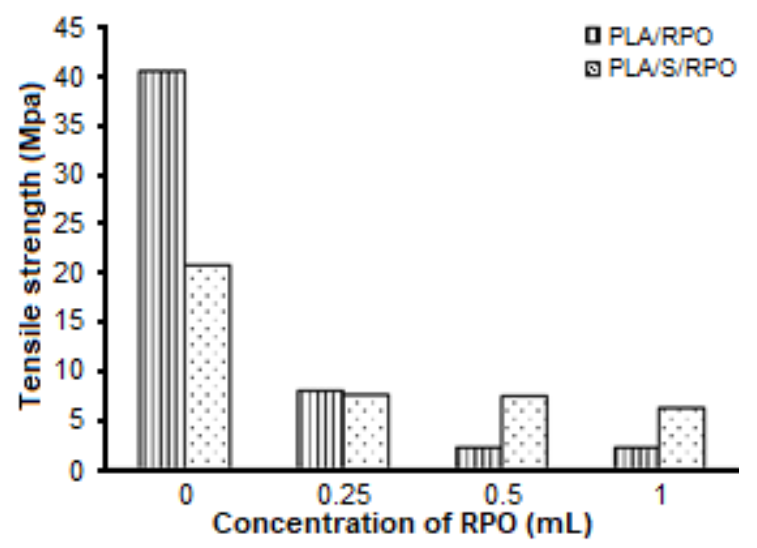

Fig 5. Tensile strength of the films
$1740 \mathrm{~cm}^{-1}$ when $\mathrm{RPO}$ was added representing $\mathrm{C}=\mathrm{O}$ stretching contributed by triglyceride ester presence in RPO. The intermolecular interactions of PLA and PLA/S were affected by the increment of RPO concentration. PLA is hydrophobic in nature; it is sensitive to moisture. This will affect the result in self-hydrolysis of carboxylic acid end groups present in PLA.

\section{Tensile Properties (Tensile Strength and Elongation Break)}

Fig. 5 shows the tensile strength of the films while Fig. 6 represent the elongation at break point of each produced film. Pure PLA possessed 40.4 MPa for its tensile strength and exhibited $4.96 \%$ at the elongation at break point. Addition of starch into PLA reduces the tensile strength from 40.4 MPa to 20.6 MPa. The tensile strength decreases with the increases concentration of RPO.

Theoretically, increase of tensile strength will decrease the elongation at break point. This is greatly opposite with the result by previous researchers [20-21]. According to Chieng et al. pure PLA typically rigid and brittle. Pure PLA had a high tensile strength but very limited elongation at break point. Adding plasticizers weakens the intermolecular forces in the film and reduce the brittleness and rigidity of the film [8] at once weaken the tensile strength. Low elongation at break point of PLA/RPO films may due to the insufficient amount of plasticizer to increase the molecular mobility and obtain more elongable film $[8,22]$. From the result, it can be seen that the ratio of PLA: RPO was not at optimum.

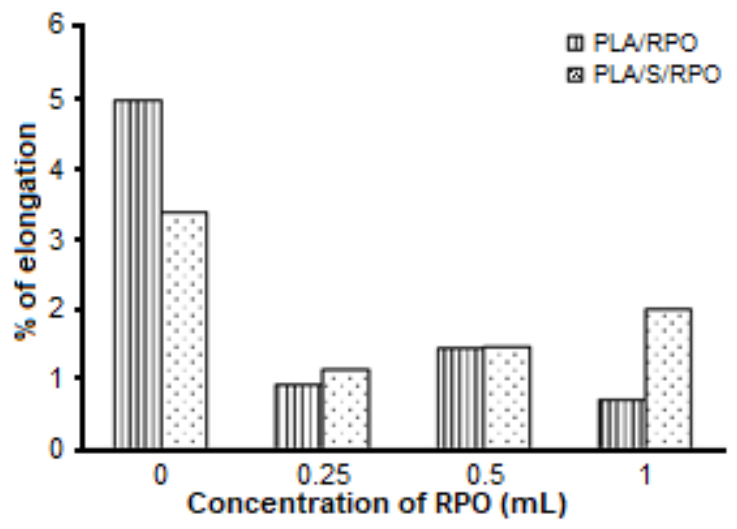

Fig 6. Elongation at break point of the films 


\section{Biodegradability Test}

Fig. 7 shows biodegradability percentage of PLA/RPO and PLA/S/RPO films. Pure PLA did not degrade throughout the process. The percentage degradation of PLA/RPO films increased when the concentration of RPO increased. After 12 days, $100 \%$ degradation occurred for PLA/S/RPO $1 \mathrm{~mL}$. As for PLA/RPO films, only PLA with $0.25 \mathrm{~mL}$ of RPO degrade $100 \%$ while the other films degrade $31 \%, 50 \%$ and $46 \%$, respectively. This shows that good biodegradable activity occurred during the degradation process. Film consisting of starch and higher concentration of RPO blends degrade greatly. The degradation process and mechanism in soil are complex and unclear as it depends on the environmental conditions. Pure PLA film requires more time than the other samples [23]. The degradation of PLA begins with hydrolysis induced by the diffusion of water into the materials, followed by the microorganisms attack and the break-down of polymer chain [11]. PLA/S/RPO films exhibited aggressive changes on degradation. The collected samples were in pieces and no complete films were collected except for the PLA/S film. The most degraded films were PLA/S/RPO $1 \mathrm{~mL}$. This proved that with the presence of starch and RPO accelerated the degradation process. Comparing to the fracture surface done by pure PLA, the structure remained unchanged even after day-12. This had been discussed by Tokiwa [23], PLA is susceptible to microbial attack in natural environment than other aliphatic polyesters [23]. This is due to the sparsely distributed PLA-degrading microorganisms in natural environment which leads to slow degradation process.

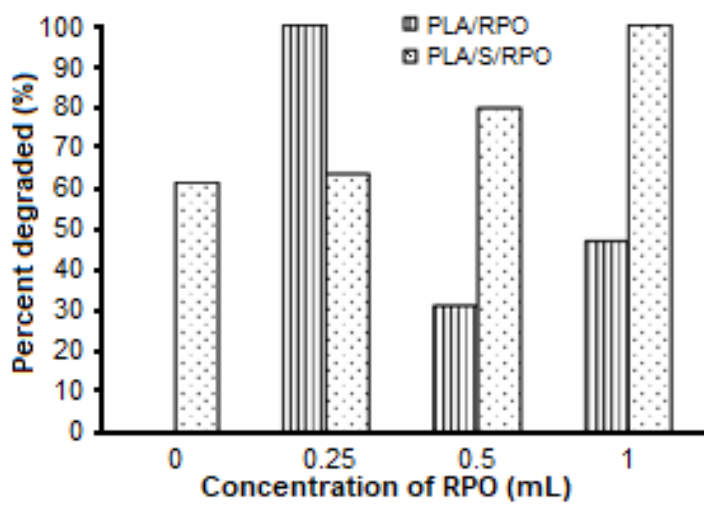

Fig 7. Biodegradation percentage of the films

\section{- CONCLUSION}

This study was conducted to produce a film packaging by combining PLA, starch and RPO. The characteristics and biodegradability properties of film were analyzed. PLA film with high concentration of RPO resulting a glossy and shiny film while addition of starch reducing the opacity of the film. The thickness of the films increases as the concentration of RPO increases and presence of starch. The FTIR results show that the structure of the PLA being altered with the presence of RPO. The addition of RPO did not positively impact the tensile strength and the elongation at break point of the films. The blends of PLA/RPO ratio did not achieve the optimum value. PLA/S with $1 \mathrm{~mL}$ of RPO degrade $100 \%$ in 12 days. These findings show that the films are a biodegradable film which fulfilled the objectives. The methods used in the film formation need to be improved. A longer mixing time are needed in order to perform a thin and clear layer of PLA/RPO film.

\section{- ACKNOWLEDGMENTS}

Thank you to Fakulti Kejuruteraan Kimia, Universiti Teknologi Mara and special appreciation to Kementerian Pendidikan Malaysia for the budget approval under RMI file number: 600-RMI/ST/FRGS 5/3/FST (37/2011).

\section{- REFERENCES}

[1] Kaya, M., Khadem, S., Cakmak, Y.S., Mujtaba, M., Ilk, S., Akyuz, L., Salaberria, A.M., Labidi, J., Abdulqadir, A.H., and Deligöz, E., 2018, Antioxidative and antimicrobial edible chitosan films blended with stem, leaf and seed extracts of Pistacia terebinthus for active food packaging, RSC Adv., 8 (8), 3941-3950.

[2] Gan, I., and Chow, W.S., 2018, Antimicrobial poly(lactic acid)/cellulose bionanocomposite for food packaging application: A review, Food Packag. Shelf Life, 17, 150-161.

[3] Tawakkal, I.S.M.A., Cran, M.J., Miltz, J., and Bigger, S.W., 2014, A review of poly(lactic acid)-based materials for antimicrobial packaging, J. Food Sci., 79 (8), R1477-R1490. 
[4] Cano, A., Jiménez, A., Cháfer, M., Gónzalez, C., and Chiralt, A., 2014, Effect of amylose: Amylopectin ratio and rice bran addition on starch films properties, Carbohydr. Polym., 111, 543-555.

[5] Vásconez, M.B., Flores, S.K., Campos, C.A., Alvarado, J., and Gerschenson, L.N., 2009, Antimicrobial activity and physical properties of chitosan-tapioca starch based edible films and coatings, Food Res. Int., 42 (7), 762-769.

[6] Wang, J., Zhai, W., and Zheng, W., 2012, Poly (ethylene glycol) grafted starch introducing a novel interphase in poly(lactic acid)/poly(ethylene glycol)/ starch ternary composites, J. Polym. Environ., 20 (2), 528-539.

[7] Koh, J.J., Zhang, X., and He, C., 2018, Fully biodegradable poly(lactic acid)/starch blends: A review of toughening strategies, Int. J. Biol. Macromol., 109, 99-113.

[8] Maniglia, B.C., Tessaro, L., Ramos, A.P., and TapiaBlácido, D.R., 2019, Which plasticizer is suitable for films based on babassu starch isolated by different methods?, Food Hydrocolloids, 89, 143-152.

[9] Piorkowska, E., Kulinski, Z., Galeski, A., and Masirek, R., 2006, Plasticization of semicrystalline poly(l-lactide) with poly(propylene glycol), Polymer, 47 (20), 7178-7188.

[10] Zulkifli, W.N.F.M., 2017, Bioplasticiser and palm oil, Palm Oil Dev., 67, 16-19.

[11] Lv, S., Zhang, Y., Gu, J., and Tan, H., 2018, Physicochemical evolutions of starch/poly(lactic acid) composite biodegraded in real soil, J. Environ. Manage., 228, 223-231.

[12] Fathima, P.E., Panda, S.K., Ashraf, P.M., Varghese, T.O., and Bindu, J., 2018, Polylactic acid/chitosan films for packaging of Indian white prawn (Fenneropenaeus indicus), Int. J. Biol. Macromol., 117, 1002-1010.

[13] Sanyang, M.L., Sapuan, S.M., Jawaid, M., Ishak, M.R., and Sahari, J., 2015, Effect of plasticizer type and concentration on tensile, thermal and barrier properties of biodegradable films based on sugar palm (Arenga pinnata) starch, Polymers, 7 (6), 1106-1124.

[14] Sanyang, M.L., Sapuan, S.M., Jawaid, M., Ishak, M.R., and Sahari, J., 2016, Development and characterization of sugar palm starch and poly(lactic acid) bilayer films, Carbohydr. Polym., 146, 36-45.

[15] Chieng, B.W., Ibrahim, N.A., Then, Y.Y., and Loo, Y.Y., 2014, Epoxidized vegetable oils plasticized poly(lactic acid) biocomposites: Mechanical, thermal and morphology properties, Molecules, 19 (10), 16024-16038.

[16] González, A., and Alvarez Igarzabal, C.I., 2013, Soy protein - Poly (lactic acid) bilayer films as biodegradable material for active food packaging, Food Hydrocolloids, 33 (2), 289-296.

[17] Tee, Y.B., Talib, R.A., Abdan, K., Chin, N.L., Basha, R.K., and Yunos, K.F.M., 2014, Toughening poly(lactic acid) and aiding the melt-compounding with bio-sourced plasticizers, Agric. Agric. Sci. Procedia, 2, 289-295.

[18] Man, Y.B.C., Haryati, T., Ghazali, H.M., and Asbi, B.A., 1999, Composition and thermal profile of crude palm oil and its products, J. Am. Oil Chem. Soc., 76 (2), 237-242.

[19] Jusoh, E.R., Ismail, M.H.S., Abdullah, L.C., Yunus, R., and Rahman, W.A.W.A., 2012, Crude palm oil as a bioadditive in polypropylene blown films, BioResources, 7 (1), 859-867.

[20] Mir, S.A., Dar, B.N., Wani, A.A., and Shah, M.A., 2018, Effect of plant extracts on the technofunctional properties of biodegradable packaging films, Trends Food Sci. Technol., 80, 141-154.

[21] Mohd Amin, A.M., Mohd Sauid, S., So'aib, M.S., Musa, M., and Ku Hamid, K.H., 2017, Mechanical and thermal properties of thermoplastic film from Tacca leontopetaloides starch reinforced with rice husk biochar, Mater. Sci. Forum, 890, 188-191.

[22] Zhang, Y., 2010, "Hydrothermal liquefaction to convert biomass into crude oil" in Biofuels from Agricultural Wastes and Byproducts, Eds. Blaschek, H.P., Ezeji, T.C., and Scheffran, J., Wiley-Blackwell, Oxford, UK, 201-232.

[23] Tokiwa, Y., and Calabia, B.P., 2006, Biodegradability and biodegradation of poly(lactide), Appl. Microbiol. Biotechnol., 72 (2), 244-251. 